\title{
Carotenoids modulate the trade-off between egg production and resistance to oxidative stress in zebra finches
}

Received: 5 July 2005/ Accepted: 8 November 2005/Published online: 10 December 2005

(C) Springer-Verlag 2005

\begin{abstract}
The allocation of resources to reproduction and survival is a central question of studies of life history evolution. Usually, increased allocation to current reproduction is paid in terms of reduced future reproduction and/or decreased survival. However, the proximal mechanisms underlying the cost of reproduction are poorly understood. Recently, it has been shown that increased susceptibility to oxidative stress might be one of such proximate links between reproduction and self-maintenance. Organisms possess a range of antioxidant defenses, including endogenously produced molecules (e.g., enzymes) and compounds ingested with food (e.g., carotenoids). If reproductive effort increases the production of reactive oxygen species, the availability of antioxidant defenses may partly or fully counteract the free-radical damages. One could, therefore, expect that the trade-off between reproduction and oxidative stress is modulated by the avail-
\end{abstract}

Communicated by Carol Vleck

S. Bertrand $(\bowtie) \cdot C$. Alonso-Alvarez $\cdot$ G. Sorci

Laboratoire de Parasitologie Evolutive,

Université Pierre et Marie Curie, CNRS UMR 7103,

75252 Paris cedex 05,

quai St. Bernard, France

E-mail: sbertran@snv.jussieu.fr

Tel: + 33-661904814

Fax: + 33-144273516

G. Devevey $\cdot$ B. Faivre

Equipe Ecologie Evolutive, Université de Bourgogne,

UMR CNRS 5561 BioGéoSciences, 6 Blvd Gabriel,

21000 Dijon, France

J. Prost

UPRES Lipides Nutrition, Université de Bourgogne,

EA 2422, 6 Bd Gabriel, 21000 Dijon, France

Present address: C. Alonso-Alvarez

Departamento de Ecoloxía e Bioloxía Animal, Universidade de Vigo. EUET Forestal, 36005 Pontevedra, Spain

Present address: G. Devevey

Département d'Ecologie et Evolution, Université de Lausanne, Bâtiment de Biologie, 1015 Lausanne, Dorigny, Switzerland ability of antioxidant defenses. We tested this hypothesis in zebra finches. We manipulated reproductive effort by either allowing or preventing pairs to breed. Within each breeding or non-breeding group, the availability of antioxidant compounds was manipulated by supplementing or not supplementing the drinking water with carotenoids. We found that although birds in the breeding and non-breeding groups did not differ in their resistance to oxidative stress (the breakdown of red blood cells submitted to a controlled free-radical attack), one aspect of breeding effort (i.e., the number of eggs laid by birds in both breeding and non-breeding groups) was negatively correlated with resistance to oxidative stress only in birds that did not benefit from a carotenoid-supplemented diet. This result therefore suggests that carotenoid availability can modulate the trade-off between reproduction and resistance to oxidative stress.

Keywords Free radicals - Carotenoids - Oxidative stress $\cdot$ Reproduction $\cdot$ Zebra finch

\section{Introduction}

A major assumption of models on the evolution of life histories is that traits do not evolve independently from one another (Roff 1992; Stearns 1992). Such trade-offs are often thought to be the result of competition for common resources. If resources are limiting, allocation to one function can only be achieved to the detriment of other functions (Zera and Harshman 2001). This paradigm has been used, for instance, to explain what is generally called the cost of reproduction (Stearns 1992) and, extensively, in the emerging field of ecological immunology (Sheldon and Verhulst 1996).

Despite the empirical evidence for the ultimate consequences of reproductive effort, the physiological mechanisms underlying the cost of reproduction remain poorly known and have only been investigated in 
the last years (Rose and Bradley 1998; Zera and Harshman 2001; Barnes and Partridge 2003). Recent work has shown that susceptibility to oxidative stress can be one of these physiological mechanisms. Experimental increase of reproductive effort in fruit flies (Drosophila melanogaster) and zebra finches ( $\mathrm{Ta}$ eniopygia guttata) has been shown to correlate with a decrease in the resistance to oxidative stress, assessed as organismal mortality to an in vivo free-radical attack (Salmon et al. 2001; Wang et al. 2001), in vitro resistance of red blood cells to a free-radical attack (Alonso-Alvarez et al. 2004a), and activity of the superoxide dismutase (Wiersma et al. 2004). Reactive oxygen species (ROS) are highly reactive molecules generated as a result of normal metabolism, which have deleterious effects on cellular components like proteins, lipids, and DNA. To counteract ROS, a complex antioxidant network exists including enzymatic (superoxide dismutase, catalase, gluthatione reductase) and non-enzymatic defenses (e.g., carotenoids, vitamins A, C, and E) (Beckman and Ames 1998; Prior and Cao 1999; Finkel and Holbrook 2000). The magnitude of oxidative stress is determined by the relative unbalance between ROS production and antioxidant defenses (Finkel and Holbrook 2000). Accumulation of damage to biomolecules caused by free radicals is recognized as a key process of somatic degeneration and aging (Harman 1956; Sohal et al. 1994; Finkel and Holbrook 2000).

Carotenoids are natural pigments synthesized by plants that are often used by animals to produce sexual signals associated with mate choice (KodricBrown 1985, 1989; Hill 1991; Badyaev and Hill 2000). The honesty of carotenoid-based signals is thought to be reinforced by two non-exclusive mechanisms. First, since carotenoids cannot be synthesized by animals and must be ingested with food, the capacity to produce carotenoid-based coloration would ultimately be linked to the individual ability to acquire or assimilate carotenoids (Endler 1980; Hill 1990). Second, carotenoids have important physiological functions as immunoenhancers and antioxidants (Chew and Park 2004; Kiokias and Gordon 2004). Therefore, if carotenoids are limiting, investing carotenoids for sexual signaling or in eggs for females would decrease their availability for the immune and detoxification systems (Lozano 1994; von Schantz et al. 1999; Alonso-Alvarez et al. 2004b). Thus, if carotenoids are a limiting resource involved in both sexual signaling and the protection against the damaging effect of free radicals, one could expect that increased availability of these compounds in the environment might partly or fully compensate the increased demand generated by reproduction.

Here, we manipulated both reproductive effort and availability of carotenoids in zebra finches and tested whether unrestricted access to carotenoids reduced the cost of reproduction in terms of resistance to oxidative stress.

\section{Material and methods}

\section{General procedure and treatments}

The study was carried out on a lab-breeding population of zebra finches. Birds were 3 month old on average (98 days) and had not bred before. They were housed in an indoor aviary maintained at constant temperature $\left(21 \pm 1^{\circ} \mathrm{C}\right)$, under controlled daily light cycles (13L:11D). Fifty-nine randomly formed pairs were held in wire cages $(0.6 \mathrm{~m} \times 0.4 \mathrm{~m} \times 0.4 \mathrm{~m})$. All individuals were provided with food (commercial seed mix) ad libitum.

Thirty pairs were provided with a nest-box and nesting material (hay) for breeding, whereas the remaining 29 pairs were prevented from breeding (no nest-box and nesting material). Similarly, half of the pairs were supplemented with carotenoids in the drinking water $\left(100 \mu \mathrm{g} / \mathrm{ml}\right.$, Oro Glo ${ }^{\mathrm{TM}}$ liquid, $11 \mathrm{mg} / \mathrm{ml}$ lutein and zeaxanthin (20:1,w/w); Kemin France SRL, Nantes, France), whereas the remaining pairs only received tap water ( $N=30$ and 29 , respectively) and this for 3 months. In a previous study, we showed that this dose $(100 \mu \mathrm{g} / \mathrm{ml})$ corresponds to the inflection point in the relationship between carotenoid availability, carotenoids in the plasma, and the expression of beak color (Alonso-Alvarez et al. 2004b). In order to avoid spatial effects in the aviary, the cages were sequentially assigned to each group (breeders with carotenoids, non-breeders with carotenoids, breeders without carotenoids, and non-breeders without carotenoids).

Every 2 days the number of eggs laid was recorded even if they were not laid in the nest-box (i.e., nonbreeders). Body weight, resistance to oxidative stress, and the amount of carotenoids in plasma were measured at the beginning of the experiment and again 3 months later. Beak color was also measured at the end of the experiment. Given that the color chart used to score beak color was not available at the starting of the experiment we do not have initial values for this variable; however, given that birds were randomly assigned to the four groups, it is unlikely that beak color differed between treatments at the beginning of the experiment. Initial values of body mass, resistance to oxidative stress, and amount of plasma carotenoids did not differ between sexes nor between breeding or carotenoid-supplementation groups (all $P \mathrm{~s}>0.20$ ), showing that initial conditions were similar for all birds (Table 1).

To assess resistance to oxidative stress and the amount of carotenoids in the plasma, blood was collected at the beginning of the experiment and 3 months later from the brachial vein into heparinized microcapillary tubes $(\sim 150 \mu \mathrm{l})$. Twenty microliters of whole blood were immediately diluted in $730 \mu \mathrm{l}$ of KRL buffer; these samples were stored at $4^{\circ} \mathrm{C}$ before analysis that occurred within $24 \mathrm{~h}$. The remaining blood was centrifuged, and plasma stored at $-20^{\circ} \mathrm{C}$ for later measurements of total carotenoid concentration. There was no difference between carotenoid supplemented and control groups in 
Table 1 Pre-experimental and post-experimental (3 months later) values of resistance to oxidative stress (min), carotenoids circulating in the plasma $(\mu \mathrm{g} / \mathrm{ml})$, and body mass $(\mathrm{g})$ (mean $\pm \mathrm{SE}$ ) for the different groups (breeders vs. non-breeders, carotenoid supplemented vs. nonsupplemented, males vs. females)

\begin{tabular}{|c|c|c|c|c|c|c|}
\hline & \multicolumn{2}{|c|}{$\begin{array}{l}\text { Resistance to oxidative } \\
\text { stress (min) }\end{array}$} & \multicolumn{2}{|c|}{$\begin{array}{l}\text { Carotenoids circulating } \\
\text { in the plasma }(\mu \mathrm{g} / \mathrm{ml})\end{array}$} & \multicolumn{2}{|l|}{ Body mass (g) } \\
\hline & Initial values & Final values & Initial values & Final values & Initial values & Final values \\
\hline Non-supplemented non-breeding males & $65.44 \pm 1.31$ & $66.04 \pm 1.97$ & $16.83 \pm 2.35$ & $30.43 \pm 3.31$ & $15.27 \pm 0.5$ & $15.59 \pm 0.77$ \\
\hline Supplemented non-breeding males & $63.15 \pm 1.18$ & $65.13 \pm 1.07$ & $20.13 \pm 2.44$ & $91.27 \pm 7.01$ & $16.71 \pm 0.71$ & $17.59 \pm 0.73$ \\
\hline Non-supplemented breeding males & $61.22 \pm 1.66$ & $65.56 \pm 1.35$ & $16.36 \pm 2.66$ & $19.33 \pm 2.44$ & $15.81 \pm 0.48$ & $15.02 \pm 0.44$ \\
\hline Supplemented breeding males & $63.74 \pm 1.28$ & $66.11 \pm 1.04$ & $18.18 \pm 2.42$ & $57.6 \pm 3.25$ & $16.17 \pm 0.56$ & $15.1 \pm 0.56$ \\
\hline Non-supplemented breeding females & $64.72 \pm 1.06$ & $65.28 \pm 1.27$ & $20.36 \pm 2.00$ & $20.93 \pm 2.12$ & $16.07 \pm 0.37$ & $15.09 \pm 0.4$ \\
\hline Supplemented breeding females & $64.86 \pm 0.89$ & $63.47 \pm 1.45$ & $19.07 \pm 3.37$ & $58.8 \pm 7.05$ & $15.97 \pm 0.44$ & $15.32 \pm 0.36$ \\
\hline
\end{tabular}

the age of the chicks when parents were sampled (supplemented breeders, mean \pm SE $38.21 \pm 1.76$ days; nonsupplemented breeders, mean \pm SE $33.14 \pm 3.66$ days, $N=17, t=-0.97, P=0.348)$.

\section{Assessment of global antioxidant defenses}

Total antioxidant defenses in whole blood were assessed as the time needed to hemolyze $50 \%$ of red blood cells exposed to a controlled free-radical attack. We used the KRL test (Brevet Spiral V02023, Couternon, France; http://www.nutriteck.com/sunyatakrl.html) adapted to bird physiological parameters (osmolarity, temperature) (Alonso-Alvarez et al. 2004a, b).

Eighty microliters of the whole blood diluted in the KRL buffer $\left(150 \mathrm{mM} \mathrm{Na}^{+}, 120 \mathrm{mM} \mathrm{Cl}^{-}, 6 \mathrm{mM} \mathrm{K}^{+}\right.$, $24 \mathrm{mM} \mathrm{HCO}-, 2 \mathrm{mM} \mathrm{Ca}^{2+}, 340$ mOsm, pH 7.4) were added to each well of a 96-well microplate. We subsequently added to each well $136 \mu \mathrm{l}$ of a $150 \mathrm{mM}$ solution of [2,2'-azobis-(amidinopropane)hydrochloride] $(646 \mathrm{mg}$ of [2,2'-azobis-(amidinopropane)hydrochloride] diluted in $20 \mathrm{ml}$ of KRL buffer), a free-radical generator (Rojas Wahl et al. 1998). The microplate was subsequently read with a microplate titrator (iEMS Reader MF, Kirial SA, Couternon, France) at $40^{\circ} \mathrm{C}$. The rate of hemolysis is determined by the change in optical density measured at $540 \mathrm{~nm}$. Previous work has shown that, if at least one component of the antiradical detoxification system is impaired, the hemolysis curve shows a shift towards shorter times (Blache and Prost 1992; Girard et al. 2005). This test therefore provides an assessment of total antioxidant defenses since all families of antioxidants present in the blood are used to fight off the oxidant attack (Blache and Prost 1992; Pieri et al. 1996; Girodon et al. 1997; Lesgards et al. 2002; Stocker et al. 2003; Girard et al. 2005).

\section{Plasma carotenoid measurement}

To determine the amount of plasma carotenoids, we used a colorimetry method. Twenty microliters of plasma were diluted in $180 \mu \mathrm{l}$ of absolute ethanol. The dilution was mixed in a vortex and the flocculent protein was precipitated by centrifuging the sample at $1,500 \mathrm{~g}$ for $10 \mathrm{~min}$. We examined the supernatant in a spectrophotometer and determined the optical density at $450 \mathrm{~nm}$. Carotenoid concentration was determined from a standard curve of lutein. We have previously shown that spectrometric and HPLC measurements of plasma carotenoids are highly correlated in zebra finches (Alonso-Alvarez et al. 2004b).

\section{Beak color}

Beak color was assessed using a Dulux Trade Colour chart (Dulux, France) under the same light conditions. The following specific scale, ranging from orange to red colors, was used: 1 (69YR 34/780), 2 (56YR 28/778), 3 (44YR 26/756), 4 (34YR 20/708), 5 (31YR 18/648), 6 (16YR 16/594), 7 (19YR 13/558), 8 (09YR 11/475), 9 (14YR 10/434), where the first number and letters indicate the hue, the numerator is the brightness, and the denominator is the saturation (Blount et al. 2003). Measurements of beak color were always performed by the same person (SB) blindly with respect to the treatments.

\section{Statistical analyses}

Change in body mass, antioxidant defenses, and plasma carotenoids over the course of the experiment were analyzed by taking the post-experimental value as dependent variable and the pre-experimental value as a covariate. Given that members of a pair share the same environment (i.e., the cage), cage identity was included in the model as a random factor. However, the cage had no effect on any of the variables (all $P_{\mathrm{S}}>0.08$ ). All the statistical analyses were performed with SAS (SAS Institute 2001).

\section{Results}

Although non-breeding pairs were not provided with a nest-box, in 16 out of 29 pairs the female laid some eggs at 
the bottom of the cage. As a consequence, the mean number of eggs laid for breeders and non-breeders was 4.9 $(\mathrm{SE}=0.40, \mathrm{~min}-\max =0-13)$ and $2.83(\mathrm{SE}=0.44, \mathrm{~min}$ $-\max =0-10)$, respectively $\left(F_{1,57}=5.97, \quad P=0.018\right)$. Laying of the first egg occurred 14 days after the start of the carotenoid supplementation. Seventeen out of 30 breeding pairs successfully reared their chicks until 40 days of age. The mean number of chicks at hatching and fledging was $2.57 \pm 0.297$ and $1.57 \pm 0.177$ (mean $\pm \mathrm{SE}, N=21$ ) for carotenoid supplemented pairs and $2.75 \pm 0.31$ and $1.88 \pm 0.272$ (mean $\pm \mathrm{SE}, N=16$ ) for non-supplemented birds (number of chicks at hatching: $F_{1,16}=0.05, P=0.820$; number of chicks at fledging: $\left.F_{1,16}=0.35, P=0.561\right)$.

\section{Body mass}

Breeders, i.e., pairs provided with a nest-box, lost more body mass over the course of the experiment than nonbreeders (Table 2, Fig. 1a). The intensity of weight loss was similar for the two sexes (Table 2, Fig. 1a) but not for the two groups of carotenoid supplementation (carotenoid-supplemented non-breeding birds gained mass, Table 2, Fig. 1b). The number of eggs laid was also related to body mass loss, with pairs laying more eggs losing more weight. However, the slope was steeper for non-supplemented birds (slope $\pm \mathrm{SE}=-0.160 \pm 0.043$ ) than for supplemented individuals (slope $\pm \mathrm{SE}=-0.088 \pm 0.053$ ) which resulted in a significant number of eggs laid by carotenoid availability interaction (Table 2). Interestingly, the effect of the number of eggs laid was similar for the two sexes as shown by the non-significant number of eggs laid by sex interaction (Table 2).

\section{Plasma carotenoids}

Individuals provided with carotenoid-supplemented water had higher amount of circulating carotenoids than control birds (Table 3, Fig. 2a). The breeding group also affected the amount of circulating carotenoids but in

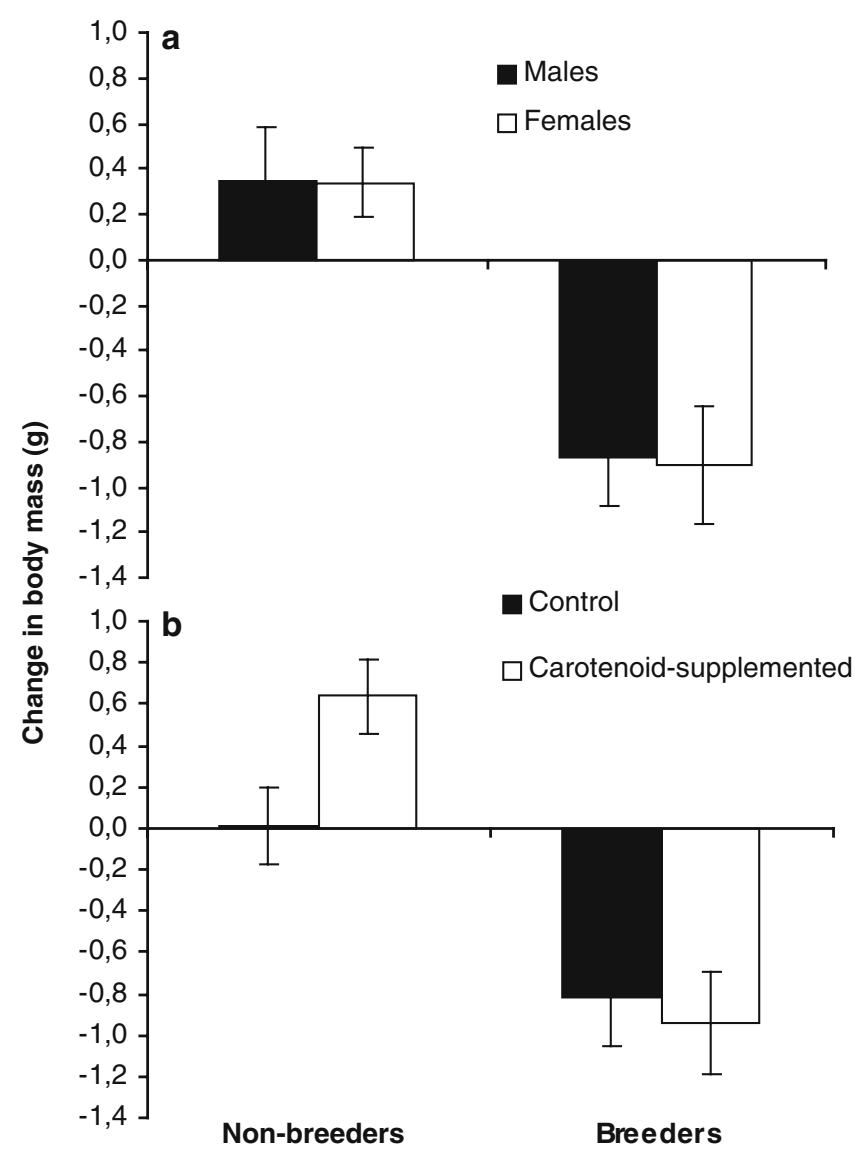

Fig. 1 Change in body mass (post-experimental minus pre-experimental values) for zebra finches (Taeniopygia guttata) prevented or allowed to breed: a males (filled bars) and females (empty bars) and b non-supplemented (control, filled bars) and supplemented with carotenoids in the drinking water (empty bars). Mean \pm SE are reported, $N=115$

interaction with sex (Table 3, Fig. 2b). Non-breeding males showed a higher increase in plasma carotenoids than breeding males, whereas the increase in plasma carotenoids of females did not differ between the two breeding groups (Fig. 2b).

Table 2 ANCOVA on the final body mass with breeding group, sex and carotenoid availability as factors and number of eggs laid and initial value of body mass as covariates. Statistically significant effects $(P<0.05)$ are reported in bold

\begin{tabular}{|c|c|c|c|}
\hline Source & $d f$ & $F$ & $P$ \\
\hline Breeding group & 1 & 6.87 & 0.010 \\
\hline Sex & 1 & 0.10 & 0.757 \\
\hline Number of eggs laid & 1 & 3.51 & 0.064 \\
\hline Initial value of body mass & 1 & 215.18 & $<0.0001$ \\
\hline Breeding group $\times$ sex & 1 & 0.01 & 0.912 \\
\hline Number of eggs laid $\times$ breeding group & 1 & 0.93 & 0.338 \\
\hline Number of eggs laid $\times$ sex & 1 & 0.11 & 0.741 \\
\hline Number of eggs laid $\times$ carotenoid availability & 1 & 5.19 & 0.025 \\
\hline Error & 103 & & \\
\hline
\end{tabular}


Table 3 ANCOVA on the final plasma carotenoid concentration with breeding group, sex and carotenoid availability as factors and number of eggs laid and initial value of plasma carotenoid concentration as covariates. Statistically significant effects $(P<0.05)$ are reported in bold

\begin{tabular}{lccc}
\hline Source & $d f$ & $F$ & $P$ \\
\hline Breeding group & 1 & 2.63 & 0.108 \\
Sex & 1 & 1.28 & 0.261 \\
Carotenoid availability & $\mathbf{1}$ & $\mathbf{5 4 . 8 3}$ & $\mathbf{0 . 0 0 0 1}$ \\
Number of eggs laid & 1 & 1.21 & 0.275 \\
Initial value of plasma carotenoids & $\mathbf{1}$ & $\mathbf{1 0 . 5 6}$ & $\mathbf{0 . 0 0 2}$ \\
Breeding group $\times$ sex & 1 & $\mathbf{5 . 6 2}$ & $\mathbf{0 . 0 2 0}$ \\
Breeding group $\times$ carotenoid availability & 1 & 0.62 & 0.432 \\
Sex $\times$ carotenoid availability & 1 & 2.33 & 0.130 \\
Number of eggs laid $\times$ breeding group & 1 & 0.21 & 0.651 \\
Number of eggs laid $\times$ sex & 1 & 0.13 & 0.720 \\
Number of eggs laid $\times$ carotenoid availability & 101 & 0.01 & 0.925 \\
Error & & \\
\hline
\end{tabular}

Beak color

Carotenoid-supplemented birds of both sexes had a redder beak than non-supplemented individuals (Table 4, Fig. 3a). Non-breeding males had a redder beak than breeding males, whereas the breeding group did not affect beak color in females (Fig. 3b). This resulted in a significant sex by breeding group interaction (Table 4). Lastly, those individuals who had a higher increase in plasma carotenoids had a redder beak $(r=0.53$, $P<0.0001, N=112)$.

\section{Resistance to oxidative stress}

Although the breeding group did not affect the resistance to oxidative stress (Table 5), pairs laying a large number of eggs had weaker antioxidant defenses than pairs laying few eggs (Table 5). However, this decrease in resistance to oxidative stress was modulated by the availability of carotenoids, as individuals with carotenoid-supplemented water maintained similar global antioxidant defenses whatever the number of eggs laid (Fig. 4a, b). This resulted in a significant number of eggs laid by carotenoid-supplementation group interaction (Table 5). Again, the effect of the number of eggs laid was not sex specific, as shown by the non-significant number of eggs laid by sex interaction (Table 5).

\section{Discussion}

We found that, although the experimental manipulation of reproduction (breeding vs. non-breeding group) did not affect the expression of antioxidant defenses, carotenoid availability modulated the relationship between one component of the reproductive effort (the number of eggs laid) and resistance to oxidative stress in zebra finches. Non-carotenoid-supplemented pairs that laid more eggs exhibited a decrease in their overall antioxidant defenses, whereas this negative correlation vanished for carotenoid-supplemented individuals. Interestingly, although egg laying is a female restricted activity, the sex by number of eggs laid interaction was not significant, suggesting that sexual behaviors, probably related to courtship and mating, were costly for males also.

The principle of resource allocation assumes that, when energy/resources are finite, increased allocation to one function cannot be achieved without a concomitant reduction of allocation to other functions (Stearns 1992). Within this framework, the cost of reproduction has attracted considerable attention from evolutionary

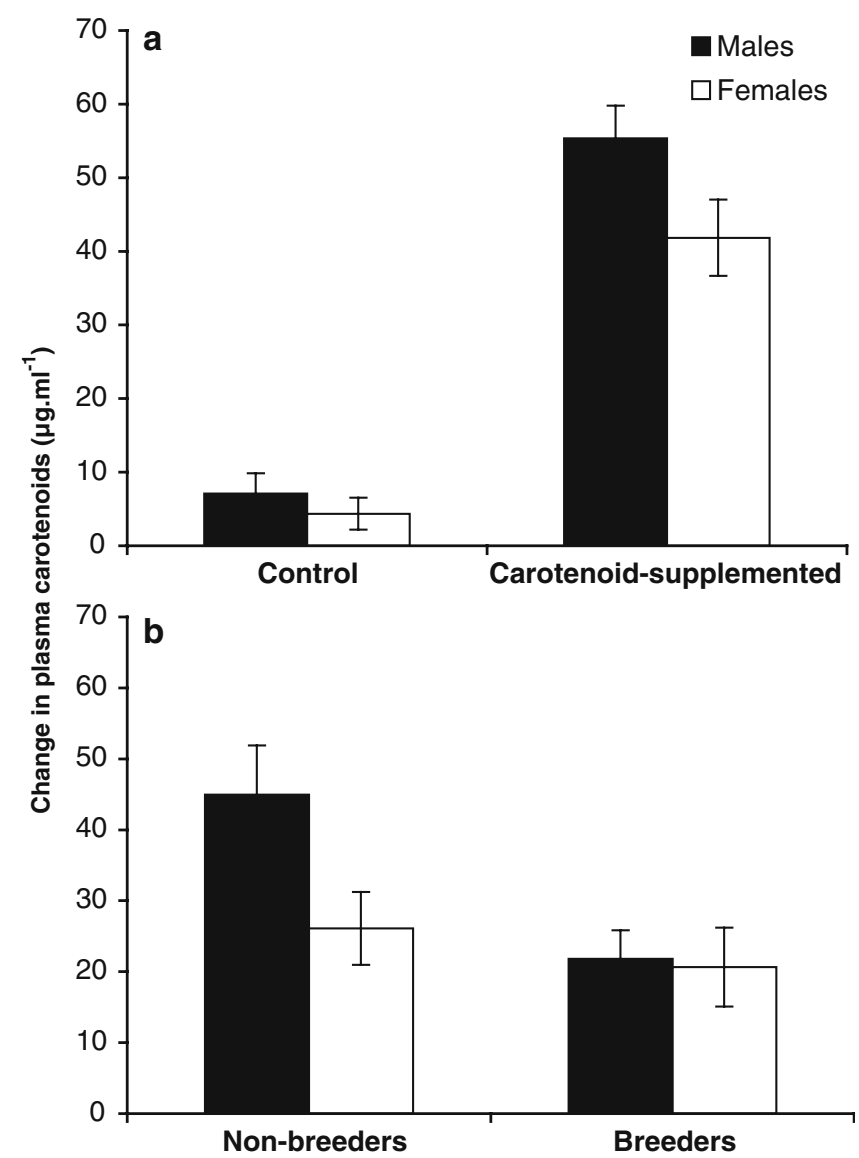

Fig. 2 Change in plasma carotenoids (post-experimental minus pre-experimental values) for male (filled bars) and female (empty bars) zebra finches: a non-supplemented or supplemented with carotenoids and $\mathbf{b}$ prevented or allowed to breed. Mean $\pm \mathrm{SE}$ are reported, $N=113$ 
Table 4 ANCOVA on beak color with breeding group, sex and carotenoid availability as factors and number of eggs laid as covariate. Statistically significant effects $(P<0.05)$ are reported in bold

\begin{tabular}{lccc}
\hline Source & $d f$ & $F$ & $P$ \\
\hline Breeding group & $\mathbf{1}$ & $\mathbf{6 . 3 4}$ & $\mathbf{0 . 0 1 3}$ \\
Sex & $\mathbf{1}$ & $\mathbf{8 6 . 2 2}$ & $<\mathbf{0 . 0 0 0 1}$ \\
Carotenoid availability & $\mathbf{1}$ & $\mathbf{3 4 . 9 2}$ & $<\mathbf{0 . 0 0 0 1}$ \\
Number of eggs laid & 1 & 3.46 & 0.066 \\
Breeding group $\times$ sex & $\mathbf{1}$ & $\mathbf{6 . 0 5}$ & $\mathbf{0 . 0 1 6}$ \\
Breeding group $\times$ carotenoid availability & 1 & 1.71 & 0.194 \\
Sex $\times$ carotenoid availability & 1 & 2.38 & 0.126 \\
Number of eggs laid $\times$ breeding group & 1 & 1.84 & 0.178 \\
Number of eggs laid $\times$ sex & 1 & 0.53 & 0.467 \\
Number of eggs laid $\times$ carotenoid availability & 1 & 0.21 & 0.647 \\
Error & 106 & & \\
\hline
\end{tabular}

ecologists (Barnes and Partridge 2003). Although a proper assessment of the cost of reproduction can be difficult because individuals might differ in their ability to gather resources rather than in their allocation rule to different functions (Reznick 1985, 1992), it is now well established that increased reproductive effort does indeed trade against future reproduction and survival (Barnes and Partridge 2003). Our short-term experimental approach did not allow us to assess the cost of reproduction in terms of longevity or future reproduction. Nevertheless, birds that engaged in reproduction

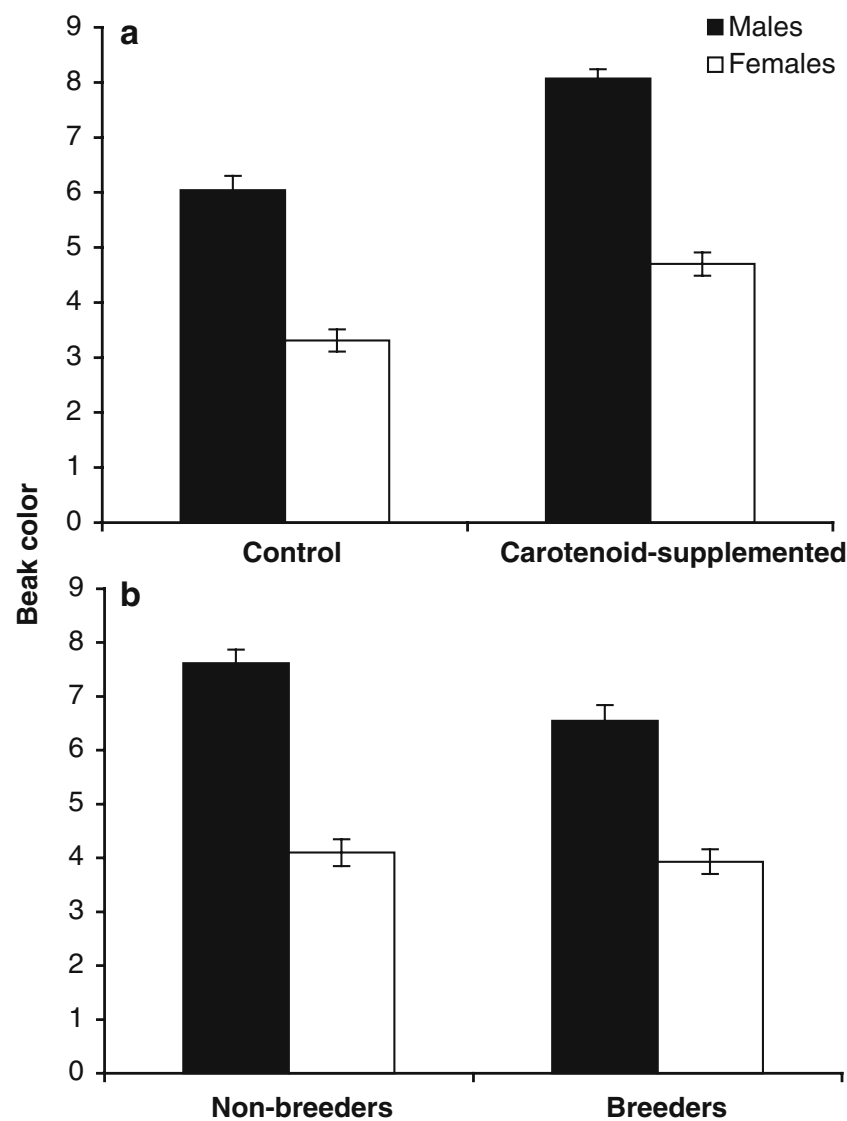

Fig. 3 Beak color, based on a specific scale described in Material and methods, of male (filled bars) and female (empty bars) zebra finches: a non-supplemented or supplemented with carotenoids in the drinking water and $\mathbf{b}$ prevented or allowed to breed. Mean $\pm \mathrm{SE}$ are reported, $N=117$ lost significantly more body mass than non-breeders and body mass can be a proxy of survival prospects in birds (e.g., Tinbergen and Verhulst 2000). This result therefore suggests that the manipulation of breeding effort was effective and produced measurable physiological costs.

The expression of the cost of reproduction can also take a more subtle form if breeding effort reduces the availability of resources necessary to the production of secondary sexual traits involved in mate choice. Two studies have reported supportive evidence for this hypothesis. The white forehead patch of male collared

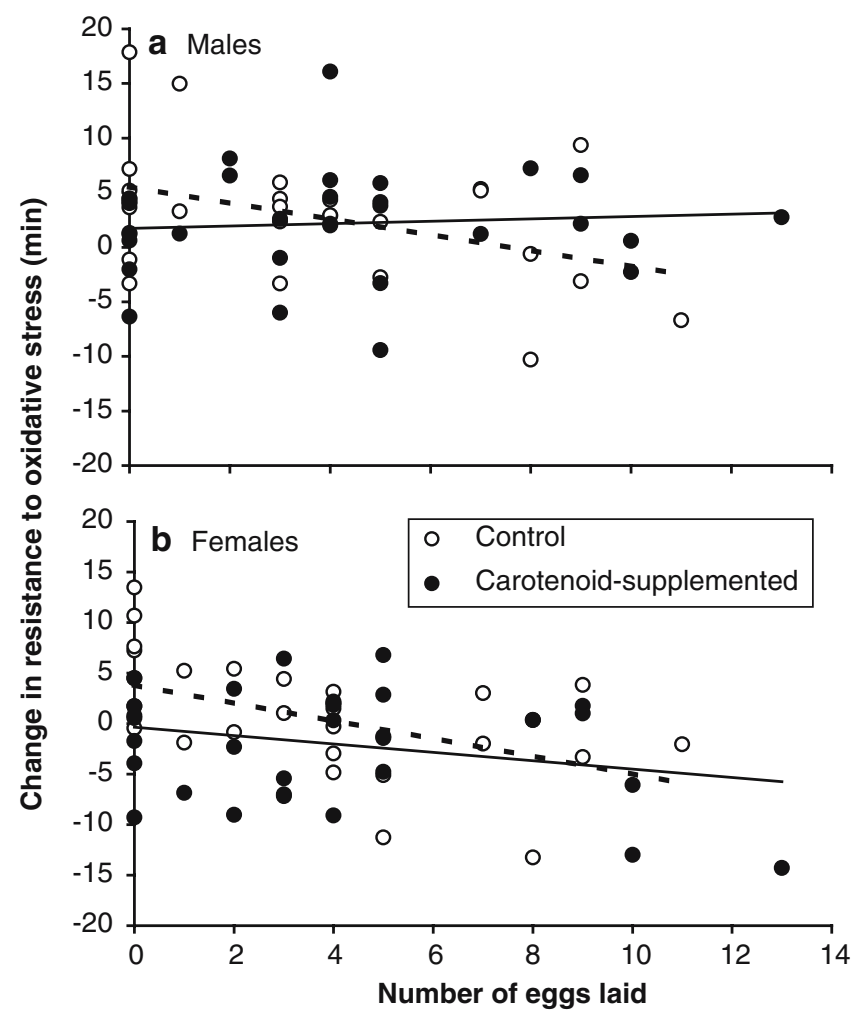

Fig. 4 Relationship between the change in resistance to oxidative stress (post-experimental minus pre-experimental values) and the number of eggs laid for non-supplemented (empty dots and dotted line) and carotenoid supplemented (full dots and solid line) zebra finches. a males (control $y=-0.7331 x+5.5551$, carotenoid supplemented $y=0.108 x+1.7235$ ), b females (control $y=-0.8862 x+$ 3.824 , carotenoid supplemented $y=-0.4146 x-0.347$ ) 
Table 5 ANCOVA on the final resistance to oxidative stress with breeding group, sex and carotenoid availability as

factors and number of eggs laid, change in body mass and initial value of resistance to oxidative stress as covariates. Statistically significant effects $(P<0.05)$ are reported in bold

\begin{tabular}{lccc}
\hline Source & $d f$ & $F$ & $P$ \\
\hline Breeding group & 1 & 0.16 & 0.694 \\
Sex & 1 & 1.32 & 0.253 \\
Carotenoid availability & $\mathbf{1}$ & $\mathbf{8 . 5 2}$ & $\mathbf{0 . 0 0 4}$ \\
Number of eggs laid & $\mathbf{1}$ & $\mathbf{1 8 . 8 8}$ & $\mathbf{0 . 0 0 0 1}$ \\
Change in body mass & $\mathbf{1}$ & $\mathbf{4 . 9 3}$ & $\mathbf{0 . 0 2 9}$ \\
Initial value of resistance to oxidative stress & $\mathbf{1}$ & $\mathbf{1 8 . 5 6}$ & $\mathbf{0 . 0 0 0 1}$ \\
Breeding group $\times$ sex & 1 & 0.60 & 0.439 \\
Breeding group $\times$ carotenoid availability & 1 & 0.05 & 0.819 \\
Sex $\times$ carotenoid availability & 1 & 1.4 & 0.240 \\
Number of eggs laid $\times$ breeding group & 1 & 1.45 & 0.232 \\
Number of eggs laid $\times$ sex & 1 & 1.22 & 0.272 \\
Number of eggs laid $\times$ carotenoid availability & $\mathbf{1}$ & $\mathbf{6 . 8 3}$ & $\mathbf{0 . 0 1 0}$ \\
Error & 102 & & \\
\hline
\end{tabular}

flycatchers (Ficedula albicollis) and the black bib of male house sparrows (Passer domesticus), that are produced during the post-breeding molt, have been shown to be sensitive to the breeding effort produced by males during the spring. Males whose brood size was increased, molted a smaller signal compared to males whose brood size was decreased (Gustafsson et al. 1995; Griffith 2000). Surprisingly, no experimental evidence exists for the effect of breeding effort on the expression of carotenoid-based sexual traits. The color of the beak of male zebra finches has been shown to become duller over the course of the breeding season both under natural and laboratory conditions (Burley et al. 1992), suggesting that breeding effort does affect the expression of the sexual signal. However, this study only reported correlative results which do not imply causation. Here, we found that breeding males had less plasma carotenoids and less red beak than non-breeding males at the end of the experiment, whereas breeding had no effect on females. Beak color is a sexually selected trait in male zebra finches, females preferring males with redder beaks (Burley and Coopersmith 1987; Blount et al. 2003, but also see Collins and ten Cate 1996). These results are consistent with theoretical expectations related to the reliability of sexual traits as indicators of individual quality (see Cotton et al. 2004 for a recent review). If the reliability of the signal depends on its condition-dependent nature, one should expect that the expression of the trait in males is more sensitive to an environmental stress than in females (Cotton et al. 2004). Our results fit into this scenario, although it would have been interesting to simultaneously assess the effect of breeding effort on the expression of non-sexually selected traits, as an appropriate control.

As mentioned above, the idea that reproduction is a costly activity makes little doubt (Reznick 1992; Zera and Harshman 2001; Barnes and Partridge 2003). More debated is the proximal currency of this cost. If, on one hand, the ultimate consequences have to be measured in terms of fitness, the proximate mechanisms underlying the cost are still largely unknown. Recently, much emphasis has been put on the role played by oxidative stress as one of such proximate mechanisms (Salmon et al. 2001; Wang et al. 2001; Alonso-Alvarez et al. 2004a; Wiersma et al. 2004). Oxidative stress results from the deleterious effect of ROS produced during the metabolic process. The accumulation of oxidative damage over time has been evoked as one of the major proximal cause of the degenerative decline in performance, also known as aging (Harman 1956; Sohal et al. 1994; Finkel and Holbrook 2000). Manipulation of reproductive effort in both insects (fruit flies) and birds (zebra finches) has shown a causal link with various aspects of resistance to oxidative stress. Drosophila stimulated to lay more eggs (either by the way of an enriched diet or by the way of an hormonal manipulation) showed a decreased resistance to in vivo exposure to paraquat, a generator of free radicals (Salmon et al. 2001; Wang et al. 2001). Similarly, zebra finches experimentally forced to raise an enlarged (six chicks) or a reduced brood (two chicks) differed in the activity of the superoxide dismutase (Wiersma et al. 2004) and in the in vitro resistance of red blood cells exposed to a controlled free-radical attack (Alonso-Alvarez et al. 2004a).

Oxidative stress is defined as the unbalance between the production of ROS and the availability of antioxidant defenses (Finkel and Holbrook 2000). If the metabolic activity enhances ROS production but at the same time antioxidant defenses are also more available, then oxidative stress should stay constant. The dynamical nature of this concept opens the way to a conditional control of the trade-off between reproduction and oxidative stress. In other terms, if antioxidant molecules are provided in excess, we expect to observe a decrease in the cost of reproduction. This is actually what we found. The number of eggs laid negatively correlated with the resistance to oxidative stress only in pairs not supplemented with carotenoids. The main effect of the breeding group (breeders vs. non-breeders) was not significant. There are several possible reasons for this pattern. First, egg laying could represent the most costly activity. Alternatively, the absence of the breeding group effect might be due to the low reproductive success of breeding pairs, which on average only produced 1.5 fledglings. The range of variation in the number of eggs laid was much higher than in the number of offspring produced and therefore there might have been more scope to catch a significant effect on egg number rather than fledgling production. 
Although the number of eggs laid was the only component of the breeding effort to correlate with resistance to oxidative stress, the negative correlation was similar for females and males. As egg laying is a female restricted activity this result might appear surprising. We suggest that a possible explanation for this result resides in the costly mating activity of males. In zebra finches, males mated with females that laid large clutches are likely to have copulated more than males mated with females that laid no eggs. Birkhead et al. (1988) reported that zebra finches copulated about 12 times for a clutch of about five eggs. Given that clutch size in our study varied between 0 and 13 , it is likely that male sexual activity (copulations, but also courting and displaying) consistently varied among pairs. Various aspects of sexual behaviors have been reported to incur costs. In birds, courtship displays can be costly in terms of energy and oxygen consumption (e.g., Vehrencamp et al. 1989; Eberhardt 1994). Similarly, copulation per se has been reported to decrease the longevity in insects (e.g., Partridge and Andrews 1985; Martin and Hosken 2004). Of course this hypothesis needs to be investigated with an experimental approach explicitly designed to test it. The similar response of males and females might also stem from the hormonal pathway involved in sexual activity. Sex hormones (testosterone and progesterone) can impair the enzymatic antioxidant defenses and lead to increased oxidative stress (see von Schantz et al. 1999 for a review of this idea and literature therein). If egg-laying activity is related to the level of circulating testosterone in males and progesterone in females, a negative correlation between number of eggs laid and resistance to oxidative stress might indirectly reflect the pro-oxidant effect of these hormones.

The rationale of our experimental design is based on the assumption that carotenoids do exhibit antioxidant properties. There has been a recent debate about the actual antioxidant function of carotenoids (El-Agamey et al. 2004; Hartley and Kennedy 2004; Kiokias and Gordon 2004). For instance, it has been suggested that carotenoids might play an antioxidant role in in vitro assays and show a pro-oxidant activity, under certain circumstances, in vivo (Hartley and Kennedy 2004). Other studies, however, show that carotenoids do exhibit antioxidant protection in vivo (Chidambara Murthy et al. 2005) and that they and their metabolic derivatives are negatively correlated to a number of ageassociated disorders (Schabath et al. 2004; Tamimi et al. 2005). We definitely need more work to establish the actual link between pigmentary, non-pigmentary antioxidants, and life history traits.

Another major assumption underlying our work is that carotenoids are limiting resources and, as such, allocation of these pigments to one function implies that less carotenoids are available for other functions. Experimental manipulation of diet carotenoids in birds has been performed in a few previous studies, and most of them have shown that increased availability affects levels of carotenoids circulating in the plasma, the expression of sexual signals, and more importantly upregulates the immune response and the antioxidant function (Blount et al. 2003; McGraw and Ardia 2003; Alonso-Alvarez et al. 2004b). The results reported in this study therefore confirm these previous findings and suggest again that carotenoid-based sexual signals are constrained by the availability of these pigments in the diet. Nevertheless, one study on goldfinches (Carduelis tristis) has failed to find an effect of dietary carotenoid supplementation on immunity (Navara and Hill 2003); this shows that we certainly need more studies to have a better picture on the role of carotenoids on both the immune and the detoxification system.

In conclusion, this study provides evidence for the role of carotenoids in the trade-off between reproduction and oxidative stress. Further experimental work should focus more on the dose-dependent effect of several antioxidant molecules over a larger range of breeding efforts.

Acknowledgements We are very grateful to Kemin France for kindly providing the carotenoids (Oro Glo ${ }^{\mathrm{TM}}$ ) used in this study. We thank the staff of the Station Biologique de Foljuif (École Normale Supérieure) for helping us to maintain the birds. Financial support was provided by the Ministère de la Recherche (ACI Jeunes Chercheurs to GS) and the Université de Bourgogne (BQR to GD, MG, JP and BF). CA-A was funded by Ministerio de Educación, Cultura y Deporte (Spain). This experiment complies with the current laws of France.

\section{References}

Alonso-Alvarez C, Bertrand S, Devevey G, Prost J, Faivre B, Sorci G (2004a) Increased susceptibility to oxidative stress as a proximate cost of reproduction. Ecol Lett 7:363-368

Alonso-Alvarez C, Bertrand S, Devevey G, Gaillard M, Prost J, Faivre B, Sorci G (2004b) An experimental test of dosedependent effect of carotenoids and immune activation on sexual signals and antioxidant activity. Am Nat 164:651-659

Badyaev AV, Hill GE (2000) Evolution of sexual dichromatism: contribution of carotenoid- versus melanin-based coloration. Biol J Linn Soc 69:153-172

Barnes AI, Partridge L (2003) Costing reproduction. Anim Behav 66:199-204

Beckman KB, Ames BN (1998) The free radical theory of aging matures. Physiol Rev 78:547-581

Birkhead TR, Pellatt J, Hunter FM (1988) Extra-pair copulation and sperm competition in the zebra finch. Nature 334:60-62

Blache D, Prost M (1992) Free radical attack: biological test for human resistance capability. In: Ponnamperuma C, Gehrke CW (eds) A lunar-based chemical analysis laboratory. Deepak A, Hampton, pp 82-98

Blount JD, Metcalfe NB, Birkhead TR, Surai PF (2003) Carotenoid modulation of immune function and sexual attractiveness in zebra finches. Science 300:125-127

Burley N, Coopersmith CB (1987) Beak color preferences of Zebra finches. Ethology 76:133-151

Burley NT, Price DK, Zann RA (1992) Beak color, reproduction and condition effects in wild and domesticated zebra finches. Auk 109:13-23

Chew BP, Park JS (2004) Carotenoid action on the immune response. J Nutr 134:257S-261S

Chidambara Murthy KN, Vanitha A, Rajesha J, Mahadeva Swamy M, Sowmya PR, Ravishankar GA (2005) In vivo antioxidant activity of carotenoids from Dunaliella salina-a green microalga. Life Sci 76:1381-1390 
Collins SA, Ten Cate C (1996) Does beak colour affect female preference in zebra finches? Anim Behav 52:105-112

Cotton S, Fowler K, Pomiankowski A (2004) Do sexual ornaments demonstrate heightened condition-dependent expression as predicted by the handicap hypothesis? Proc R Soc Lond B 271:771-783

Eberhardt LS (1994) Oxygen consumption during singing by male Carolina wrens Thryothorus ludovicianus. Auk 111:124-130

El-Agamey A, Lowe GM, McGarvey DJ, Mortensen A, Phillip DM, Truscott TG, Young AJ (2004) Carotenoid radical chemistry and antioxidant/pro-oxidant properties. Arch Biochem Biophys 430:37-48

Endler JA (1980) Natural selection on color patterns in Poecilia reticulata. Evolution 34:76-91

Finkel T, Holbrook NJ (2000) Oxidants, oxidative stress and the biology of ageing. Nature 408:239-247

Girard A, Madani S, El Boustani ES, Belleville J, Prost J (2005) Changes in lipid metabolism and antioxidant defense status in spontaneously hypertensive rats and Wistar rats fed a diet enriched with fructose and saturated fatty acids. Nutrition 21:240-248

Girodon F, Blache D, Monget AL, Lombart M, Brunet-Lecompte P, Arnaud J (1997) Effect of a two-year supplementation with low doses of antioxidant vitamins and/or minerals in elderly subjects on levels of nutrients and antioxidant defense parameters. J Am Coll Nutr 16:357-365

Griffith SC (2000) A trade-off between reproduction and a condition-dependent sexually selected ornament in the house sparrow Passer domesticus. Proc R Soc Lond B 267:1115-1119

Gustafsson L, Qvarnström A, Sheldon BC (1995) Trade-offs between life-history traits and a secondary sexual character in male collared flycatchers. Nature 375:311-313

Harman D (1956) Aging: a theory based on free radical and radiation chemistry. J Gerontol 11:298-300

Hartley RC, Kennedy MW (2004) Are carotenoids a red herring in sexual display? Trends Ecol Evol 19:353-354

Hill G (1990) Female house finches prefer colourful males: sexual selection for a condition-dependent trait. Anim Behav 40:563-572

Hill G (1991) Plumage coloration is a sexually selected indicator of male quality. Nature 350:337-339

Kiokias S, Gordon MH (2004) Antioxidant properties of carotenoids in vitro and in vivo. Food Rev Int 20:99-121

Kodric-Brown A (1985) Female preference and sexual selection for male coloration in the guppy (Poecilia reticulata). Behav Ecol Sociobiol 17:199-206

Kodric-Brown A (1989) Dietary carotenoids and male mating success in the guppy: an environmental component to female choice. Am Nat 124:309-323

Lesgards JF, Durand P, Lassare M, Stocker P, Lesgard G, Lanteaume A (2002) Assessment of lifestyle effects on the overall antioxidant capacity of healthy subjects. Environ Health Perspect 110:479-487

Lozano GA (1994) Carotenoids, parasites, and sexual selection. Oikos 70:309-311

Martin OY, Hosken DJ (2004) Copulation reduces male but not female longevity in Saltella sphondylli (Diptera:Sepsidae). J Evol Biol 17:357-362

McGraw KJ, Ardia DR (2003) Carotenoids, immunocompetence, and the information content of sexual colors: an experimental test. Am Nat 162:704-712

Navara KJ, Hill GE (2003) Dietary carotenoid pigments and immune function in a songbird with extensive carotenoid-based plumage coloration. Behav Ecol 14:909-916
Partridge L, Andrews R (1985) The effect of reproductive activity on the longevity of male Drosophila melanogaster is not caused by an acceleration of ageing. J Insect Physiol 31:393-395

Pieri C, Moroni F, Marra M (1996) Food restriction increases the protection of erythrocytes against the hemolysis induced by peroxyl radicals. Mech Ageing Dev 87:15-23

Prior RL, Cao G (1999). In vivo total antioxidant capacity: comparison of different analytical methods. Free Radic Biol Med 27:1173-1181

Reznick D (1985) Costs of reproduction: an evaluation of the empirical evidence. Oikos 44:257-267

Reznick D (1992) Measuring the costs of reproduction. Trends Ecol Evol 7:42-45

Roff DA (1992) The evolution of life histories: theory and analysis. Chapman \& Hall, New York

Rojas Wahl RU, Zeng L, Madison SA, De Pinto RL, Shay BJ (1998) Mechanistic studies on the decomposition of water soluble azo-radical-initiators. J Chem Soc Perkin Trans 2 9:20092018

Rose MR, Bradley TJ (1998) Evolutionary physiology of the cost of reproduction. Oikos 83:443-451

Salmon AB, Marx DB, Harshman LG (2001) A cost of reproduction in Drosophila melanogaster: stress susceptibility. Evolution 55:1600-1608

SAS Institute (2001) SAS/STAT Software: changes and enhancements, Version 8.2. SAS Publishing, North Carolina

Schabath MB, Grossman HB, Delclos GL, Hernandez LM, Day RS, Davis BR, Lerner SP, Spitz MR, Wu X (2004) Dietary carotenoids and genetic instability modify bladder cancer risk. J Nutr 134:3362-3369

von Schantz TV, Bensch S, Grahn M, Hasselquist D, Wittzell H (1999) Good genes, oxidative stress and condition-dependent sexual signals. Proc R Soc Lond B 266:1-12

Sheldon B, Verhulst S (1996) Ecological immunology: costly parasite defences and trade-offs in evolutionary ecology. Trends Ecol Evol 11:317-321

Sohal RS, Ku HH, Agarwal S, Forster MJ, Lal H (1994) Oxidative damage, mitochondrial oxidant generation and antioxidant defenses during aging and in response to food restriction in the mouse. Mech Ageing Dev 74:121-133

Stearns SC (1992) The evolution of life histories. Oxford University Press, New York

Stocker P, Lesgards J-F, Vidal N, Chalier F, Prost M (2003) ESR study of a biological assay on whole blood: antioxidant efficiency of various vitamins. Biochem Biophys Acta 1621:1-8

Tamimi RM, Hankinson SE, Campos H, Spiegelman D, Zhang S, Colditz GA, Willett WC, Hunter DJ (2005) Plasma carotenoids, retinol, and tocopherols and risk of breast cancer. Am J Epidemiol 161:153-160

Tinbergen JM, Verhulst S (2000) A fixed energetic ceiling to parental effort in the great tit? J Anim Ecol 69:323

Vehrencamp SL, Bradbury JW, Gibson RM (1989) The energetic cost of display in male sage grouse. Anim Behav 38:885-896

Wang Y, Salmon AB, Harshman LG (2001) A cost of reproduction: oxidative stress susceptibility is associated with increased egg production in Drosophila melanogaster. Exp Gerontol 36:1349-1359

Wiersma P, Selman C, Speakman JR, Verhulst S (2004) Birds sacrifice oxidative protection for reproduction. Proc R Soc Lond B Suppl 271:360-363

Zera AJ, Harshman LG (2001) The physiology of life-history tradeoffs in animals. Annu Rev Ecol Syst 32:95-126 